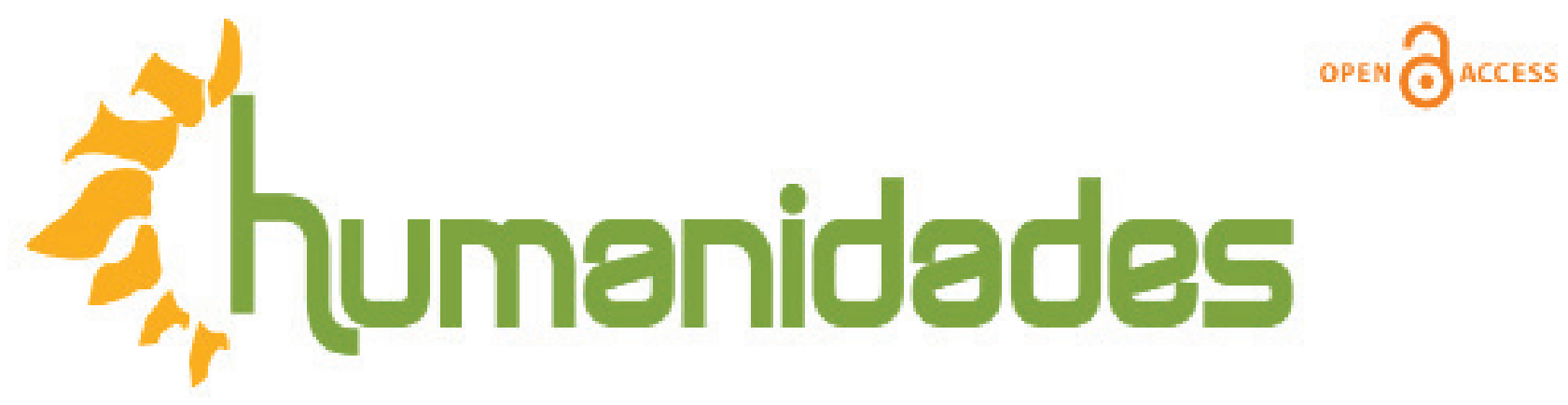

Revista de la Escuela de Estudios Generales, Universidad de Costa Rica

Enero-julio, 2019 •Volumen 9, número 1 • EISSN 2215-3934 • pp. 1-46

Recibido: 23-Octubre-2018 Aceptado: 28-Noviembre-2018

\title{
Una crítica a la investigación del pensamiento latinoamericano
}

DOI: https://doi.org/10.15517/h.v9i1.35345

\section{César Augusto Pérez Jiménez}

Doctor en Ciencias Humanas. Profesor Asociado de la Universidad del Zulia, Venezuela.

Correo electrónico: cesar.augusto.perez.jimenez@gmail.com

Todos los derechos reservados. Universidad de Costa Rica. Esta revista se encuentra licenciada con Creative Commons. Reconocimiento-NoComercial-SinObraDerivada 3.0 Costa Rica. Correo electrónico: humanidades@ucr.ac.cr/ Sitioweb: http: //revistas.ucr.ac.cr/index.php/ humanidades 


\section{Una crítica a la investigación del pensamiento latinoamericano}

\section{Resumen}

Este trabajo presenta una crítica a la praxis de la investigación sobre el pensamiento latinoamericano a partir de la problematización sobre lo territorial y lo humano en perspectiva histórico-epistemológica. Esta crítica, de carácter argumentativo, parte de la comprensión del territorio como lugar de enunciación de los intersticios creados entre la conquista y la colonia para orientar el estudio sobre la nominalidad de América como parte de la geopolítica moderno-colonial. Asimismo, examina cómo a partir del nombramiento del territorio, se erigió un proyecto civilizador que empañó el desarrollo auténtico y original de las culturas raizales como parte de las imposiciones de textualidades económicas y políticas emplazadas en la constitución del Estado liberal-ilustrado, las cuales facilitaron la producción de un proyecto pedagógico civilizador orientado a la subalternización de los pueblos originarios. Finalmente, establece un espacio para la discusión sobre los requerimientos de una metodología de investigación del pensamiento latinoamericano como preámbulo a la búsqueda de sentidos en la praxis liberadora de la investigación sobre el pensamiento latinoamericano.

\section{A Critique of the Research on Latin American Thought}

\begin{abstract}
This work presents a critique of the praxis of research on Latin American thought from the problematization of the territorial and the human in a historical-epistemological perspective. This critique, of argumentative nature, derives from the understanding of the territory as a place of enunciation of the interstices created between the conquest and the colony to guide the study of the nominality of America as part of the moderncolonial geopolitics. It examines how, from the designation of the territory, a civilizing project was erected that marred the authentic and original development of the initial cultures as part of the imposition of economic and political textualities located in the constitution of the liberal-enlightened state, which facilitated the production of a civilizing, pedagogical project oriented towards the subalternization of native peoples. Finally, it establishes a space to discuss the requirements of a methodology for the investigation of Latin American thought as a preamble to the search for meanings in the liberating praxis of research on Latin American thought.
\end{abstract}

Palabras clave:

investigación, pensamiento latinoamericano, territorio, estado liberal-ilustrado
Keywords: research, Latin American thinking, territory, liberal-enlightened state 


\section{Desde dónde se hace la crítica}

La tarea suscrita en esta discusión comporta el ejercicio de la argumentación sobre lo que pretendemos sea una crítica acerca de ciertos fundamentos supuestos en la producción de conocimiento sobre las realidades latinoamericanas, específicamente desde lo conocido como pensamiento latinoamericano, esta vez relacionado con la colonialidad del territorio y el sentido lógico de americanidad instalado por efecto de la conquista europea y la formación de la conciencia de nuestros pueblos originarios. Esta crítica se realiza desde una perspectiva teórica sobre aspectos históricos, políticos y culturales desarrollados por quienes se han dedicado al estudio del pensamiento latinoamericano y que han producido conocimiento, muchas veces, a partir del encargo de evidenciar los hechos narrados desde la memoria raizal y, en otros casos, como parte de los análisis teórico-metodológicos propiamente filosóficos e históricos derivados de la racionalidad científica. Esta discusión, por tanto, se presenta como una aproximación hipotética orientada a develar el carácter histórico-epistemológico del territorio en la construcción de prácticas de significación nuestro-americanas ${ }^{1}$, las cuales han emergido desde la violenta dominación conquistadora y se mantienen vigentes, aunque con matices estéticos edulcorados por la retórica de la globalización y el neoliberalismo.

Este trabajo no busca sugerir metodologías de investigación sobre el pensamiento latinoamericano ni crear falsas imágenes sobre los eruditos dedicados a ese campo de investigación; pero, sí pretende incorporar o replantear el sentido determinante de la colonialidad del territorio sobre la determinación de un proyecto políticofilosófico que ha orientado la creación de una cosmovisión americana diseñada desde la perspectiva euro-estadounidense ${ }^{2}$ para problematizar sobre lo latinoamericano y la visibilización universal de nuestras cosmogonías raizales. A la vez, se consideran los aportes del acervo de saberes históricos constituido e institucionalizado para la legitimación del sentido universal de la humanidad, el mundo y la realidad, del saber y del conocimiento, sobre todo, porque esta reflexión se sustenta en una intencionalidad trans-in-disciplinaria.

Estas cavilaciones fueron dando cuerpo a un conjunto de problematizaciones entretejidas sobre algunos cabos sueltos encontrados, comúnmente, en la tradición 
metodológica de lo que conocemos como filosofía latinoamericana. Primero, pensar la investigación del pensamiento latinoamericano conlleva definir las implicaciones histórico-epistemológicas evidenciadas en los campos disciplinarios referidos al estudio de las realidades latinoamericanas; esta perspectiva debe incorporar otras narrativas sobre lo humano y la realidad provenientes de la literatura, las artes, el urbanismo y, sobre todo, de los saberes sociales producidos desde la memoria histórica local. Esta proposición conduce a considerar la producción de conocimientos y saberes latinoamericanos más como un campo de pensamiento amplio y profundo, aun con fertilidades por cultivar, referido al pensamiento no como una unidad meramente mental, intelectual, sino como una estructura compleja establecida sobre las experiencias de latinoamericanidad confinadas a subalternidades ${ }^{3}$ impuestas, a dominaciones permanentes $y$ constantes y a la invisibilización de esos modos de vida originarios sin historia ${ }^{4}$.

Segundo, pensar en la investigación sobre el pensamiento latinoamericano implica, de forma inaplazable, precisar el lugar de enunciación de los aspectos epistemológicos, teóricos y metodológicos adoptados para "investigar" las realidades latinoamericanas. Por tanto, la problematización sobre la investigación del pensamiento latinoamericano debe afianzarse en la comprensión del fenómeno territorial que desde la conquista supuso la razón subyacente a los intereses del Estado monárquico al ocupar nuestra-América, y de la manera en que el territorio fue institucionalizado mediante un cuerpo jurídico, entendido como un sistema de verdad finamente diseñado para el control de la vastedad del suelo y el subsuelo americano, de sus pobladores, sus modos de vida, pero, sobre todo, de sus economías y sistemas políticos. Una investigación sobre la experiencia latinoamericana apartada de la problematización histórico-epistemológica sobre el territorio apunta con éxito al descrédito.

Tercero, para un sector de intelectuales latinoamericanos es necesario mantener y profundizar, reflexiva y críticamente, los diálogos de saberes con las racionalidades euro-estadounidenses prevalecientes en la filosofía "universal". En efecto, muchos de nuestros filósofos, académicos e intelectuales locales fueron formados desde 
esas lógicas, siguiendo sus principios y métodos, pero la vivencia propia, contextual, localizada, favoreció y continúa favoreciendo el desarrollo de cuerpos teóricos y filosóficos orientados a comprender nuestras luchas, necesidades y condiciones materiales de existencia en un mundo convulso y ecodepredador destinado a ser propiedad de unos pocos y arriendo de muchos. El propósito de pensar en, sobre, desde y para Latinoamérica radica, precisamente, en revelar nuestras condiciones de existencia situadas históricamente como circunstancias propiamente latinoamericanas, sin apegos a reproducciones técnicas de otros modelos filosóficos, teóricos o científicos, pero sí tensionando nuestras ideas con esos "grandes relatos universales", reconociendo los derroteros históricos y políticos que cada escuela de pensamiento ha confrontado para revolucionar el mundo de las ideas de su época. A la vez, debemos saber incorporar nuestras estrategias intelectuales, críticas y argumentativas para re-crear otras lógicas desde esa manera de lugarización de lo pensable, específicamente, lo latinoamericano (Guadarrama González, 2008; Dussel, 1996). Esta posición no desestima la existencia de sectores académicos e intelectuales, incluso políticos, que determinan el desarrollo de un conocimiento tribal basado en planteamientos entretejidos desde la lógica europea y estadounidense, desde una ciencia para la modernización y una estrategia económico-política para la dominación hegemónica de territorios ajenos; no son zonas que puedan verse separadamente, menos cuando buena parte del pensamiento decolonial se ha gestado y difundido desde los escenarios académicos estadounidenses, así como otras perspectivas críticas nacidas desde la hegemonía central, desde el corazón mismo de los sistemas de dominación.

Problematizar y pedagogizar el pensamiento latinoamericano y sus formas metodológicas para investigarlo es una labor intelectual sustentada en el compromiso con las historias y sabidurías de los pueblos silenciados por la lógica de la conquista incardinada en la matriz colonial del poder ${ }^{5}$, además, representa una obligación para la formación de la conciencia orientada sobre valores humanos necesarios para el tensionamiento permanente de las identidades y ciudadanías implicadas en una praxis liberadora. Por estas razones, es relevante reconocer la importancia de pensar el territorio como contexto para la problematización sobre Latinoamérica, así como pensar la acción histórico-filosófica como desafío intelectual para crear conciencias y provocar inspiraciones para accionar un proyecto liberador y presentar algunos criterios orientadores de la praxis investigadora en este fecundo campo de ideas. 


\section{Enunciación colonial del territorio}

El reconocimiento del territorio como categoría problematizadora en la investigación del pensamiento latinoamericano constituye un engranaje indispensable al momento de orientar su formulación teórico-metodológica, pues conlleva identificar el carácter determinante del emplazamiento de la práctica investigadora: el lugar desde donde se hace, de donde emerge el investigador, el problema, lo teórico, lo metodológico, de cara a profundizar en la trama de relaciones subyacentes a la producción problematizadora. Esta vía de reflexión apunta a reconocer la relevancia del territorio y de la colonialidad como una fórmula de contextualización sobre las realidades económicas, políticas, históricas, sociales y culturales de los pueblos latinoamericanos, especialmente, en el escenario histórico-epistemológico desarrollado en torno a la radicalización de la dependencia y la servidumbre ancladas al imaginario latinoamericano.

Las características atribuidas a este fenómeno evidencian cómo se fueron desarrollando los mecanismos y las tecnologías de poder y control para subalternizar a los pueblos originarios con el propósito de sustraer las riquezas naturales asentadas en la geografía americana. Es el caso expuesto por Felipe Guaman Poma de Ayala, consciente de su presente colonial, al afirmar que "en este tiempo se descubrió las Indias del Perú y hubo nueva en toda Castilla y Roma de cómo era tierra en día India (...), y así fue llamado tierra en el día, India, tierra de riqueza de oro y plata" (1980, p. 35 , la cursiva es nuestra) ${ }^{6}$, un territorio cuyas bondades fueron saqueadas con planificada precisión:

En este tiempo se aliñaron y se armaron para embarcarse a las Indias por embajador del gloriosísimo emperador don Carlos rey de Castilla, y fue señalado don Diego Almagro y don Francisco Pizarro, capitanes, y con la codicia de las Indias de oro y plata, hubo alboroto en toda Castilla, y para venirse se ajuntaron ciento y setenta y dos soldados... (Poma de Ayala, 1980, p. 35, la cursiva es nuestra)

Así, los hechos fueron ocurriendo: se adoctrinaba a los nativos para la servidumbre y la obediencia a las lógicas del ego-conquistador, en el nombre de Dios se evangelizó, 
se alfabetizó, se violentó, se dominó y se despojó a los pueblos originarios de todos los bienes que poseían por naturaleza de su habitabilidad en esos territorios. Como lugar de enunciación, el territorio, como contexto y lugar, material y concreto, desde donde se producen las intenciones interpretativas sobre las realidades latinoamericanas, revela el adosamiento a intereses económicos y políticos, principalmente, puestos sobre el suelo y subsuelo conquistado mediante específicos instrumentos geográficos, jurídicos y legales dirigidos a ordenar no sólo el territorio, sino el cuerpo social y cultural de los seres descubiertos (Brito Figueroa, 1973). ${ }^{7}$ Por lo tanto, todo proyecto evangelizador, alfabetizador $y$ adoctrinador se dirigía específicamente al desbravecimiento de la conciencia originaria y al consecuente despojo de sus posesiones y dominios, de modo que sus organizaciones sociales, con sus características económicas, políticas y culturales, figuraron como destinatarias de la dominación para ejecutar la explotación natural de las tierras americanas; para nosotros, esta premisa fundamenta la colonialidad del territorio.

En este sentido, resulta impostergable evidenciar la precisión de la lógica de la colonialidad del territorio al intentar explicar cómo el surgimiento de las tramas de significación conquistadora, traducidas en acciones concretas de ocupación, saqueo y domesticación de la vida natural y humana de nuestra-América, fueron concretadas en la invasión del territorio y la imposición de la razón conquistadora, borrando violentamente toda posibilidad de expresión autóctona. Este escenario ha servido para orientar la reproducción y la justificación del ejercicio de las relaciones de poder concebidas y fortalecidas desde el hecho de la conquista y perfeccionadas a través del fortalecimiento de la racionalidad científica eurocéntrica destinada a establecer las prescripciones para el funcionamiento del orden mundial, para la legitimación liberal-ilustrada de la gubernamentalidad y, con ello, de la universalización hegemónica de prácticas ideológicas y económico-políticas normativas, normalizadoras y totalizantes. ${ }^{8}$

A través de la implementación del derecho de propiedad territorial contenido en la legislaturamonárquica,"en las colonias hispanoamericanas eldominio absoluto sobre la tierray demás condiciones naturales de la producción, correspondía—porprincipio 
y derecho de conquista - al Estado metropolitano" (Brito Figueroa, 1973, p. 11). Este cuerpo jurídico facultaba la acentuación de la racionalidad colonial y una práctica colonialista para legitimar la forma en que se podía regular legalmente el territorio según los intereses conquistadores, así como las mentalidades y subjetividades de las organizaciones sociales originarias con el único propósito de ordenarlas como población, doblegar sus sistemas de convivencia y civilidad, someterlas al servicio de la explotación de sus propias posesiones. Evidencia de ello es el goce de los beneficios obtenidos en los territorios ocupados, que "consistían en repartimiento de solares y tierras de pastos o labor, y de indios o de otros labradores", (Brito Figueroa, 1973, p. 15, destacado en el original) pues:

conjuntamente con las ocupaciones de hecho y la incorporación de la mano de obra indígena y de los esclavos de origen africano al proceso productivo, se desarrolla la propiedad privada agraria en el sentido absoluto, coexistiendo en la realidad y en las normas legales, con otras modalidades de uso, posesión y propiedad de la tierra. (Brito Figueroa, 1973, p. 16)

El territorio ultrajado de acuerdo a las instrucciones dadas desde la metrópoli, además, contó con una planeación geográfica contenida en los mapas elaborados donde se adicionaba el nuevo mundo, resquebrajando la idea de unicidad y universalidad presumida por la Europa occidental. También se creó una forma de nombrar ese territorio desde la latinidad (Mignolo, 2007), ${ }^{9}$ además de las tensiones que produjo el nombrar las "provincias" recién encontradas en los albores del siglo XVI. Así, la idea de América no sólo era explotada, violentada y cartografiada, sino que era nombrada y sistemáticamente alienada a un esquema de vida que trazaba acciones de orden económico, político, histórico, social y cultural articuladas entre sí para dar continuidad a las lógicas de la dominación inscritas en la racionalidad moderno/colonial, entre las que resaltan la purificación de sangre y el lavado de cerebro. Nombrar el territorio supuso identificarlo con una serie de principios rectores del orden civilizatorio impuestos a partir de la conquista, madurado con la asunción del Estado liberal-ilustrado y difundido mediante la visibilización de las intenciones contenidas en los corpus del pensamiento científico, expandidos mediante la estrategia colonizadora de renovadas prácticas alfabetizadoras y evangelizadoras ${ }^{10}$ de aquellos seres inferiores, carentes de espíritu, propios de una tierra salvaje, o sea, aquellos seres pobladores de nuestro territorio raizal. 
Nombrar algo es parte de una creación. La tesis de la invención de América es una afirmación epistemológica a favor de la formación del sistema-mundo moderno/colonial descrito mediante la dialéctica del poder surgida en el seno del imperialismo occidental sobre el territorio "descubierto" (Dussel, 1994; Quijano y Wallerstein, 1992; Mignolo, 2007). Puesto en marcha el proyecto civilizatorio en el nuevo mundo, se aseguraba la incorporación de nuestros-originarios en la línea de la lógica de la modernidad con el único propósito de radicalizar la razón y la praxis colonial, pues resultaba necesario legitimar la distribución de los bienes, riquezas y beneficios de las tierras americanas para concentrar el poder económico mundial en manos de los conquistadores-dominadores, en vista de que el resultado resultado fuese la proyección de una geometría asimétrica de relaciones geopolíticas centro-periféricas con diferencias sustanciales en cada espacio geográfico colonizado, es decir, que la colonización y su aparato semiótico de dominación funcionó de manera diferenciada en cada región de la América, pero anclada a la lógica moderno-colonial asentada en el sistema-mundo ${ }^{11}$.

Ante las bondades territoriales de la América y de la despótica vida a la que eran sometidos sus pobladores por sus destructores los españoles, durante el movimiento independentista y emancipador americano - más cercano de su expectativa anfictiónica-, Simón Bolívar informaba a un caballero jamaiquino, mediante epístola unionista, el valor de nuestro territorio "por su posición física, por las vicisitudes de la guerra y por los cálculos de la política" (Bolívar, 2010, p. 63), ${ }^{12}$ valores que también habían ocupado el pensamiento emancipador de Francisco de Miranda. Agrega el Libertador: "nosotros somos un pequeño género humano; poseemos un mundo aparte, cercado por dilatados mares, nuevo en casi todas las artes y ciencias aunque en cierto modo viejo en los usos de la sociedad civil” ( $p$. 70). Con ello no sólo se refiere a un sello de identidad, sino que fundamenta una completa argumentación a favor de la unión de los pueblos en virtud de consagrar la debilitada independencia lograda con anterioridad, así que sobre la base de advertencias y exhortaciones explica al detalle la significancia del territorio, su cuidado y protección para el despliegue de una forma de gobierno; al respecto, el Libertador problematiza el orden del territorio para fundar una forma de gobierno “porque un Estado demasiado extenso en sí mismo o por sus dependencias, al cabo viene en decadencia y convierte su forma libre en otra tiránica; relaja los principios que deben conservarla y ocurre por último el despotismo" (p. 79). 
Al fragor de la independencia y la emancipación, el territorio fue adquiriendo relevancia económica y política en los ideales mirandino y bolivariano. La calidad estratégica ceñida en torno a los pactos y alianzas para alcanzar con éxito el desplazamiento y la desocupación total de las fuerzas metropolitanas de la tierra americana significaron replanteos geográficos importantes, causa de los embates que tuvo que enfrentar nuestra-América. Miranda, durante su estancia en Europa en 1798 y en 1801, concibió dos proyectos constitucionales para el continente americano y no logró el éxito esperado (Grases, 2010), pero quien escribe el prólogo del libro de José María Antepara, Miranda y la emancipación suramericana, sí alcanzó a diseminar la idea sobre "las inmensas riquezas que encierra la América del sur y sobre el gran papel que ésta podría jugar en el contexto mundial, una vez dueña de su propio destino" (Bohórquez, 2009, p. XIII).

Entre los logros del insigne Miranda, la organización de la forma de gobierno lucía amplia e inclusiva pues consideraba que la tierra americana debía enrumbarse con autonomía e independencia, a pesar de sus cercanas negociaciones de esta empresa con los ingleses y de aprovechar el espacio de la opinión pública, lo cual entredecía si el interés subyacente era la libertad americana o un nuevo tutelaje gubernamental, esta vez inglés y liberal-ilustrado. El impulso emancipador de Miranda derivó en una propuesta constitucional e institucional profundamente reflexiva y crítica de la realidad vivida en el espacio meridional; en palabras de Bohórquez:

\footnotetext{
América vive una situación de opresión y tiene todo el derecho a emanciparse; Inglaterra puede y le conviene ayudar a esta emancipación; para ello, el propio Miranda ha diseñado un proyecto militar y se ha preparado así mismo para conducirlo; $y$, finalmente, los hispanoamericanos, aunque han estado sumidos en la ignorancia hasta ese momento, lo apoyarán con entusiasmo tan pronto se les provea de información alternativa y de argumentos convincentes sobre la maldad de España y sobre las enormes ventajas de la libertad. (2009, p. XX)
}

La transversalidad histórica de las ideas creadas sobre nuestra-América expone el amarre económico-político al proyecto ideológico de ocupación, control y expansión sobre nuestros-territorios, destinado a la formación de una conciencia, una cultura y una identidad legitimadas en el mismo contenido de su enunciación, lo cual fue avizorado por los ilustres independentistas. Atendiendo a estas consideraciones, la investigación del pensamiento latinoamericano debe ser inducida por las textualidades histórico-epistemológicas recreadas a partir de la incorporación del 
territorio como problematización filosófica, humanística y social. El reto es considerar los valores del territorio como lugaridad a la vez que productor de realidades económicas, políticas y sociales particulares que han definido un imaginario y unas prácticas enclaustradas en la lógica de la dependencia. Brito Figueroa (1973) expone con detalle la dinámica presentada:

La realidad económica y social (...) terminó por imponerse sobre la letra y el espíritu de las normas jurídicas elaboradas por el Estado metropolitano, pero interpretadas y aplicadas en los territorios conquistados (...), en función del desarrollo histórico concreto de las fuerzas productivas y de las relaciones de producción que sometían las leyes a sus intereses, y no a la inversa, no como piensan quienes estudian la historia económica de las colonias hispanoamericanas, no desde el punto de vista de lo típico y real que en ellas se desarrolla sino basados exclusivamente en el texto de las normas jurídicas, que el Estado metropolitano elaboraba para ejercer el dominio político pleno en los territorios conquistados. (p. 20, destacado en el original)

La claridad filosófica y política sobre la enunciación de América y la comprensión de lo territorial, considerando las contradicciones y encuentros ocurridos en torno a esta problematización, sobre todo los circunscritos al ámbito económico-comercial, constituye un aspecto medular para orientar nuestras intenciones indagadoras sobre el pensamiento latinoamericano, más cuando intentamos profundizar en la comprensión de las ideas y prácticas comunes y actuales recreadas en una América del siglo XXI donde se borronean sus memorias históricas de dominación, opresión, luchas y victorias y en su lugar surgen vanas admiraciones de ese otro-contrarioconquistador.

Con precisión reflexiona Carmen Bohórquez (2008) cuando señala que:

dejar de ser "reflejo de ajena vida" fue la meta que plantearon nuestros libertadores y tal hecho tiene mucha más significación histórica que la marcha imperial del espíritu europeo sobre el planeta, en tanto la primera es lucha por la reivindicación del ser propio, por la afirmación de la propia humanidad. (p. 11)

A partir de los argumentos hasta ahora planteados, surgen inquietudes éticas e intelectuales orientadas a producir un cuerpo de reflexiones sobre los relatos asimétricos producidos desde las lógicas de la dominación materializadas en el pensamiento liberal-ilustrado, a la vez ejecutadas mediante las estrategias narrativas 
de la modernización, la dependencia y el desarrollo que germinaron en la primera mitad del siglo XX y ejecutadas especialmente en Latinoamérica. Hipotéticamente, asumimos que la dependencia, tal como la plantean los teóricos del desarrollo, integra en su discusión los principios elementales de la colonialidad del territorio y la fundación de la nación y la ciudadanía asociada a la creación de identidades acordes a los contenidos ideológicos moderno-coloniales y a la producción histórico-epistemológica de la instauración del pensamiento liberal-ilustrado. De este modo, las luchas locales para formular unas filosofías plurales y dialógicas entre los pueblos, centradas en la comprensión de sus patrones de dominación y en las posibilidades de fundar acciones liberadoras, deben surgir del reconocimiento crítico de la cosmogonía del territorio habitado y productor de los bienes primarios de una nación; suponer el territorio como contextualidad y textualidad para decolonizar la práctica del pensamiento latinoamericano supone establecer diálogos centrados en indagar sobre la formación del ser americano.

\section{La permanente purificación de América}

La particularidad de universalidad teórica y epistemológica pretendida desde el campo filosófico e histórico instalada sobre el territorio nombrado y conocido como América Latina, ha estado sujeta a los dogmatismos establecidos desde los cánones de la lógica y la abstracción filosófica creados en el seno de la cuna del saber, esto es desde Europa con su historia, su política, su periodización, su autenticidad, su identidad y su proyecto hegemónico científico y sociocultural claramente definido por los límites de la occidentalización.

Con el imaginario apuntalado en la cultura helénica y el pensamiento occidental, el eurocentrismo circuló como doctrina geopolítica del conocimiento sobre el ser y el poder, fundado en la periodización histórica de los hechos mundiales de significación cultural, siempre visto desde la hibris y sustentado en la racionalidad de la modernidad y textualizado a partir del cogito-europeo, fue desterrando otras formaciones culturales incluso de mayor relevancia (Dussel, 2007; Zea, 1975; Castro-Gómez, 2005). 
El descubrimiento materializado del territorio americano desde y por Europa, lo convierte en un espacio de tensiones y disputas implicadas en una trama de relaciones globales sobre la legitimidad geopolítica del poder, imaginado desde esa Europa circunscrita a intereses mercantilistas expansionistas con respecto a una América, un nuevo mundo, con organizaciones sociales, económicas, políticas y culturales extrañas según lo establecido en lo creído como normal en el proyecto civilizador eurocentrado. Ese nuevo mundo no podía ser considerado ni válido ni normal, en todo caso pudiera ser calificado como un apéndice ulterior de la cultura proveniente de la metrópoli y una real amenaza para ésta (cfr. Dussel, 1994), pues, sin duda alguna, la ocupación europea de nuestras tierras americanas produjo una serie de eventos ejecutados y justificados desde su propia lógica y estrategia de ser conquistadores de lo desconocido, desconocido para quien no lo había vivido como evidencian los propósitos testimoniados en sus viajes exploratorios; 13 finalmente, se institucionalizó un sistema de opresión y dominación que formó las conciencias raizales como conciencias dependientes de una estructura de pensamiento y comportamiento hegemonizado por sus hacedores europeos, ratificando la diferencia colonial a partir de la lógica del racismo. Asimilada y profundizada la lógica de la diferencia colonial, del racismo y de la dominación, se demandaba una transformación dirigida hacia la libertad.

En el marco de las independencias y emancipaciones nuestro-americanas, una vez lograda la misión de ruptura con la dominación política instaurada desde la metrópoli, el imaginado proyecto de libertad, autonomía, soberanía y la conformación independiente de naciones republicanas continuaba confrontando tensiones y presiones sobre la posesión del territorio. Desde el seno de tales proyectos se instauró la idea de ser poseedor de bienes, ajenos por cierto, para consolidar las estructuras de poder dispuestas en la acrecentada jurisprudencia de la propiedad privada que tanto benefició a los metropolitanos y perjudicó a nuestros pueblos originarios; surgieron nuevos conceptos de organización social que produjeron un replanteamiento de sus principios y fundamentos a fin de consolidar los florecientes desarrollos científicos y jurídicos europeos, los cuales estuvieron destinados a razonar las justificaciones de los intereses económicos y políticos eurocéntricos puestos sobre los territorios americanos. Este proceso implicó una pedagogización de la personalidad y el carácter de los cuerpos subjetivos originarios, desde la cual se orientó sus formas 
de pensar, de creer, de ser y hacer en relación con los privilegios otorgados por sus colonos. Sucedía, entonces, que los propios pobladores de las tierras americanas eran siervos de sus colonizadores, siervos en los territorios que por derecho natural les pertenecían y que fueron saqueados para satisfacción de los propósitos mercantiles y económicos de la metrópoli, desplazando sus auténticas cosmogonías por una supuesta cultura superior.

Lo que en principio se imaginó como un proyecto libertador y emancipador, históricamente fue luciendo como una desventura política, provocadora de agitaciones y movimientos destinados a la renovación y transformación republicana, inspirados en ideales de libertad y productores de cambios inminentes ante el mutismo cotidiano reinante en la tierra americana, una vez que fuera libertada mediante propósitos de unión concertados en el ideario de la Patria Grande, así, la ruptura de lazos que la unía con la España comportaría el reconocimiento del "hábito de la obediencia; un comercio de intereses, de luces, de religión; una recíproca benevolencia; una tierna solicitud por la cuna y por la gloria de nuestros padres; en fin, todo lo que formaba nuestra esperanza provenía de España" (Bolívar, 2010, p. 64), ${ }^{14}$ y de allí, el levantamiento en fuerza de pueblos confusos pero unidos en las intenciones de emancipación, de pueblos que han continuado en la búsqueda permanente de un sentido propio de ser americano y coexistir en un mundo hegemónico señalado como modelo económico y político que, anclado en el pensamiento liberal-ilustrado, pretendió regresar las tierras libres a las cadenas de la subyugación, ahora con otras textualidades estéticas, pero colonialista siempre, enfocadas en el despojo del territorio y en la consolidación de la subalternización de sus pobladores.

Sobre la fertilidad productiva de las tierras americanas se impuso cierto estilo de vida inspirado en el librecambismo y el tradicionalismo católico; además, la mirada colectiva de los intelectuales se volvió, ante todo, sobre el contrato social y los derechos humanos para optar por los preceptos de "igualdad y democracia expresados también en la independencia de los Estados Unidos y mal planteados en el mundo latinoamericano, donde la igualdad se concibió solamente entre "señores", sin considerar siquiera proyectarla hacia abajo" (Bosch García, 2006, p. 240). De modo que, la independencia fue más bien un acto político-administrativo 
que socio-cultural e intelectual, razón suficiente para que los pensadores liberales e ilustrados vieran a bien provocar un movimiento emancipador de las ideas y de las mentalidades, incluso Domingo Sarmiento proponía incorporarse al progreso a través de la asimilación del ejemplo de civilización estadounidense, pues era menester aprender de las grandes ideas para adentrarse en el progreso modernizador y deslastrarse del conflicto de las razas, impedimento para los desarrollos creídos como necesarios para los pueblos americanos (Zea, 1986; Sarmiento, 1915). Planteaba Sarmiento citado por García:

En "Civilización y Barbarie" limitaba mis observaciones a mi propio país; pero la persistencia con que reaparecen los males que creíamos conjurados al adoptar la Constitución federal, y la generalidad y semejanza de los hechos que ocurren en toda la América española, me hizo sospechar que la raíz del mal estaba a mayor profundidad que lo que accidentes exteriores del suelo lo dejaban creer. Usted conoce lo que pasa en el Pacífico desde Chile hasta Ecuador, penetrando hasta Bolivia, y tiene más cerca el espectáculo que presentan Méjico y Venezuela, en cuanto a realidad de sus proclamadas instituciones, y necesito darle una ligera idea, por estar más distante de lo que pasa por acá y motiva estos estudios. (Ibídem, p. 44)

Con tales declaratorias, remitidas a Mrs. Horace Mann en diciembre de 1883, respetado político y curador artístico estadounidense, miembro del partido liberal y fundador de las escuelas comunes, Sarmiento daba por afirmado el retroceso al que había llegado la América con respecto a la determinante influencia estadounidense y continúa alegando: "Para nuestro común atraso sud-americano avanzamos ciertamente; pero para el mundo civilizado que marcha, nos quedamos atrás" (1915, p. 45); asimismo, destaca las bondades de la situación material argentina en contraposición con los pesares políticos acaecidos por la débil experticia para gobernar, con lo cual quedaba expuesto su malestar con el 'desarrollo local', y sentencia:

Hemos educado cuatro mil doctores en leyes desde 1853, en que se reorganizaron las universidades. (...) Nosotros educamos uno para cada quinientos, y, sin embargo, en las Cámaras y Congresos, en los consejos y ministerios cada vez ignorase más el derecho. (...) Este es el estado de nuestras gentes, duchos en la discusión, rebeldes en la práctica. (Ibídem, p. 46) 
Mientras tanto, para Juan Bautista Alberdi fue primordial avizorar una "educación que permitiese a sus hombres hacer lo que otros ya habían hecho en Europa y Norteamérica" (Zea, 1986, p. XI), siendo necesario recolonizar la idea americana originaria, mirar las ilustrísimas culturas y políticas euro-estadounidenses:

\begin{abstract}
Gobernar es poblar en el sentido que poblar es educar, mejorar, civilizar, enriquecer y engrandecer espontánea y rápidamente, como ha sucedido en los Estados Unidos. Más para civilizar por medio de la población, es preciso hacerlo con poblaciones civilizadas; para educar a nuestra América en la libertad y en la industria es preciso poblarla con poblaciones de la Europa más adelantada en libertad y en industria, como sucede en los Estados Unidos. (Alberdi, 1915, pp. 14-15)
\end{abstract}

Lo que fue luego de la gesta independentista y emancipadora distaba de sus concepciones originales, para los forjadores de la libertad de las tierras americanas, la independencia suponía la superación del tutelaje político dispuesto por la monarquía metropolitana. Así, cuando Miranda procuró la asistencia inglesa para impulsar la independencia de América, no obvió el interés geopolítico estratégico de Inglaterra sobre las tierras que fueran atribuidas por propiedad a la metrópoli, ni el riesgo de mantener la tan despreciada relación súbdito-soberano resignificada mediante alianzas fundadas en la concepción de una república continental, proyecto que conllevaba unidad cultural y una estrategia política transformadora de las estructuras políticas, jurídicas y económicas de las "sociedades americanas" (cfr. Bohórquez, 2009, p. XXXI).

En tanto, Bolívar en su Carta de Jamaica argumentaba sobre la grandeza mundial de la América toda, gobernada a partir de la fórmula política republicana, pues nuestros pueblos necesitaban "de los cuidados de gobiernos paternales que curen las llagas y las heridas del despotismo y la guerra" (Bolívar, 2010, p. 78), y para ello se debía lidiar con las contradicciones políticas de los partidos que aspiraban direccionar la gubernamentalidad de nuestra-América, por ello ratifica que "el interés bien entendido de una república se circunscribe en la esfera de su conservación, prosperidad y gloria" (p. 79), y mientras esos partidos seguían apegados a formar una idea política americana ajena a las realidades propias, imitando la composición y dinamismo de otras repúblicas, 
el Libertador planteaba sus formulaciones sobre la gubernamentalidad en torno a la significación geopolítica del territorio mediante análisis minuciosos de cada porción de tierra americana y la forma de gobierno que debía serle favorable, siempre con la mira puesta en la unión de los pueblos en una sola y gran nación.

La línea argumentativa hasta ahora planteada, bocetada como una breve aproximación a un problema de mayor alcance, como lo es la conformación política de la independencia de las naciones, conduce a subrayar la formación de las identidades americanas frente al valor político y económico establecido por la fuerzas hegemónicas internas y externas a la gran nación americana sobre el territorio, y, por otra parte, resalta las controversias suscitada en el análisis de la ideología política que orientaba la constitución de los gobiernos republicanos para la conducción de las nuevas naciones. En suma, apuntamos la discusión sobre la idea de la conformación del espíritu político nuestro-americano y la formación de identidades propias, sobre todo en materia política, como inspiración para diseñar las formas de gobierno que debían regir las repúblicas, las cuales han estado allegadas a la línea estratégica sugerida por los relatos librecambistas que predominaron en la época colonial americana, según la cual las subjetividades y sociedades más adecuadas eran aquellas que aprendieran la servidumbre natural y la entrega desinteresada de sus posesiones como valores colectivos para el mantenimiento del orden de la civilidad. A esta situación se adiciona, la organización de clases y su vinculación con los principios establecidos en el contrato social y los derechos del hombre, transferidos mediante la educación popular y técnica, donde el imaginario euro-estadounidense se constituía en la clave organizativa social, dejando a los pueblos originarios en desventajas socio-culturales, políticas y económicas ante sus colonos, ahora vistos como la cúspide de una estructura social impuesta desde la racionalidad liberal-ilustrada, mientras que la intención de forjar un sentido lógico nuestro-americano se sometía a una búsqueda permanente.

Con la independencia americana como hecho político-administrativo pero no como un hecho social y cultural, la intelectualidad emancipadora se condujo alrededor de las aspiraciones de configurar la subjetividad originaria semejante a la de sus modelos culturales de identidad y socialización, aceptando la penetración de los más claros valores dominantes de la industrialización estadounidense y europea a 
la vida común nuestro-americana, donde la economía se ceñía, primeramente, a la producción agrícola. Por tanto, no puede sernos extraño encontrar planteamientos como los realizados por el movimiento intelectual argentino y mexicano, quienes apegados al positivismo, encontraron sentido a la valoración del desarrollo de otras culturas, poniendo en desventaja las propias; bien lo decía Alberdi (1915):

Todo lo que es civilizado es europeo, al menos de origen; pero no todo lo europeo es civilizado; y se concibe perfectamente la hipótesis de un país nuevo poblado con europeos más ignorantes en industria y libertad que las hordas de la Pampa o del Chaco. (p. 16)

Ideas como esta fueron muestras de cómo iba acentuándose la producción del racismo de Estado, la organización de la gubernamentalidad política reposaba claramente en la división de las naciones mediante la clasificación del territorio y una experticia detallada de las características naturales propias de cada zona geográfica, por lo cual elementos como el clima, el tipo de suelo, las actividades desarrolladas a partir de la calidad topográfica, entre otras, iban definiendo el carácter y la personalidad originaria. La subjetividad se percibía salvaje, bárbara, por tanto domesticable, educable, en este contexto se pensaba en la pureza de sangre y en el lavado de cerebro, esto es, "La América Latina, si ha de ser parte de la civilización, tendrá que ser deslatinizada, tendrá que adquirir la sangre y la mente de Europa que encarna esta civilización” (Zea, 1986, p. XI).

La adquisición de sangre refería directamente a la aceptación sobrevalorada de la inmigración para la rectificación de la raza, la purificación de la filogenia originaria, con la llegada de extranjeros provenientes de las repúblicas modélicas se auguraba la transformación de la población, se acentuaba la creencia de la transmisión de linajes y privilegios adquiridos por naturalización de nacionalidad y, sobre todo, se legitimaba el orden y control de la población. Mientras tanto, el lavado de cerebro se circunscribía. exclusivamente. al perfeccionamiento del mundo de las ideas, de las mentalidades e intelectualidades, también a la emancipación del espíritu mediante la superación de los hábitos coloniales para resistir nuevas formas de colonialismo, pero a la vez sugería replantearse una recolonización para desterrar la ignorancia de los pueblos (Zea, ob. cit., p. XIV y sucesivas). 
En todo caso, la educación constituía la legítima institucionalización de la transformación de las mentalidades, siempre adosada a la estructura política y económica liberal-ilustrada establecida por la hegemónica racionalidad euroestadounidense.

Ambos procesos, pureza de sangre y transformación de la mentalidad, estuvieron vinculados históricamente al establecimiento del linaje europeo de comprobada calidad; en nuestra-América estos procesos estuvieron relacionados al "principio de control, de orden social, político y religioso de las provincias de ultramar por parte de la Metrópoli” (Almarza, 2009, p. 7), por tanto y dada su jurisdicción impuesta desde la racionalidad implicada en las relaciones de poder provenientes de la metrópoli:

la limpieza de sangre se convirtió en la base ideológica de un sistema de estratificación social jerárquica, basada en el origen del individuo: español, indio o negro y fue utilizado como mecanismo efectivo para excluir a los nativos originales de América. (Almarza, 2009, p. 8)

De esta manera, pensadores como Sarmiento y Alberdi, entre otros, consideraron la noción biologicista sobre la raza frente a la civilización para mantener las naciones en el marco del orden y progreso de inspiración positivista, consideraban la cultura propia en atraso con respecto a las luces de la cosmogonía euro-estadounidense, y veían en la inmigración desde estas latitudes haciaAmérica la respuesta a la evolución de la raza propia y al desarrollo de las ideas necesarias para fortalecer el espíritu republicano y el racismo de estado ${ }^{15}$. Para Alberdi (1915) gobernar era poblar, gobernar implicaba poblar mediante procesos educativos dirigidos al ordenamiento de la población mediante la floreciente economía política de mediados del siglo XIX; para el pensador, poblar significaba purificar el perfil racial de la población argentina, primeramente, pero sus ideas se fueron expandiendo al compás de las grandes ideas enciclopedistas sobre el orden social de las poblaciones, discutido desde el siglo XVIII en la Europa científica moderno-colonial. . En estos contextos metropolitanos, la distinción del europeo con respecto a los otros territorios y sus culturas por ellos conocidos condujo el desarrollo del pensamiento liberal-ilustrado en función de la discriminación entre blancos y negros, hombres y mujeres, niños 
y adultos, ciudadanos y no ciudadanos, así como otras dicotomías que sirvieron de bastión para consolidar la población ideal para el óptimo funcionamiento de los procedimientos económicos y políticos que, desde la Europa dominante, llegarían a la indómita América para, como señaláramos antes, impulsar el orden y el progreso continental.

Sin lugar a dudas, la meridiana claridad de quienes forjaron nuestra independencia y emancipación superaba con atino el criterio geopolítico sobre el que se desarrollaron las relaciones con los nuevos colonizadores de nuestra-América. Mientras que para Miranda, Bolívar, incluso para Gual y España, había que desterrar toda huella española de la América y formar una identidad nacional acordada según el pacto republicano de la unión de los territorios, para los emancipadores intelectuales era necesario volver la mirada hacia la añeja racionalidad de la colonialidad euro-estadounidense. Impactada por el desarrollo tecnológico que favorecía la apertura comercial y comunicacional entre diferentes regiones mediante obras civiles adecuadas a las necesidades de modernizar las repúblicas, la emancipación incorporó la retórica racista en la institucionalidad del Estado mediante la purificación de sangre, el blanqueamiento epistemológico y la transformación de las intelectualidades a través de acciones estrictamente educativas. La pedagogización entronada en la estructura del Estado liberal-ilustrado, legitimada por cuerpos jurídicos finamente establecidos teórica y políticamente, estaba centrada en el perfeccionamiento de las habilidades, las moralidades y en el comedimiento de las libertades, en formar ciudadanos aptos para la vida pública y controlados estratégicamente para el resguardo de los intereses nacionales, o más bien, transnacionales, pues los intereses de las repúblicas fueron aquellos dictados por las hegemonías euro-estadounidenses para salvaguardar la paz y la democracia en la región latinoamericana. ${ }^{16}$

La línea racional encontrada en la narrativa liberal-ilustrada que acobijó el pensamiento latinoamericano en el transcurso del siglo XIX hasta mediados del siglo XX, en medio de importantes movimientos transformadores, deja evidencia de la existencia de una estrategia de subalternización de los pueblos proveniente de la idea de modernidad científica que florecía sobre América en nuestra-América, se trataba de una permanente purificación de lo americano. En este sentido, la 
idea de América Latina rondaba los márgenes de una estética de la subalternidad, entendida como la composición significativa mediante símbolos testimoniales del apego irrestricto a formar fatuas heterogeneidades, según repúblicas existieran, a favor de la profundización de una orientación hegemónica desde donde se delineaba la concepción de Estado y sujeto histórico-nacional demandado para la radicalización de los proyectos de penetración euro-estadounidenses en materia económica, política y cultural. Para ello, se debía producir un estamento de saberes que sirvieran de guía para socavar el locus de la colonialidad y la estructura dinámica subalternizadora que correspondía históricamente por pactos y alianzas a nuestros pueblos.

Con base en los contenidos económicos y políticos instaurados por el orden liberalilustrado, la formación educativa de los colonizados sobre la estructura social, el pensamiento económico y las ideas y comportamientos políticos, debía circular entre las organizaciones sociales que conformaban las nacientes repúblicas y constituía un asunto de primer orden. Este modelo educativo fundó sus bases sobre la lógica del racismo, para que estos territorios liberados lograran un desarrollo de potencialidades, urgía lo que antes referíamos como pureza de sangre y lavado de cerebro, un proceso de domesticación de la raza, pero de una raza específica y necesaria (Vázquez y Pérez Jiménez, 2012, p. 28).

Con la mirada reposando sobre los ideales de libertad y dominio propio, la América colonial da lecciones sobre la formación de subjetividades, mentalidades, pero también de identidadesy ciudadanías pensadas fuera de laidea raizal de americanidad. Si antes indicábamos que se borroneaba la memoria histórica originaria de la herida colonial, descrita por la lucha de los pueblos por la propia determinación nacida de sus territorios y su convivencia en ellos, con la profundización y refinamiento estratégico del pensamiento liberal-ilustrado y el avance científico-tecnológico del positivismo, así como el desplazamiento de formas rebeldes de pensamiento insurgente, sencillamente se impusieron taxonomías estructurales hegemónicas de universalización para invisibilizar toda expresión de barbarie de la superficie territorial americana y acrecentar la estratégica purificación de la americanidad. 
El proyecto civilizatorio moderno-colonial fortalecido, ha avanzado hacia otra forma de alfabetización de los pueblos a través de estrategias de opresión y precisado las tácticas políticas para el ordenamiento del territorio, de la población, de su economía, por lo cual esa alfabetización ha transcurrido asentada en el espíritu jurídico de la igualdad entre los hombres, en la procura de sus derechos humanos y con base al contrato social de civilidad normalizadora euro-estadounidense. Mientras la Europa occidental modelaba los cuerpos científicos, filosóficos y jurídicos, a través de su desarrollo teórico en los novedosos campos de las ciencias positivas, los Estados Unidos continuaban posicionándose como el ejemplo nacional de republicanismo y constitucionalismo para las emergentes naciones inexpertas en materia de libertades, mediadas por los significados materiales de la adopción de la economía política como doctrina económico-política (Bosch García, 2006) ${ }^{17}$ De modo que la geopolítica de la colonialidad ha asegurado el éxito de su bitácora afinando detalles para el mantenimiento histórico de la hegemonía de la normalización universal de las identidades, las ciudadanías, los derechos y las libertades, ello sobre la base de 'pactos y alianzas' de cooperación para el desarrollo de las crecientes naciones americanas; obviamente, se hizo sumamente necesario educar las masas, educarlas para la subalternización, la servidumbre y la acción industriosa.

Desde el pensamiento liberal-ilustrado se administró y reforzó la invisibilización de las identidades gestadas en el seno de los pueblos originarios de nuestra-América, con ello también se negó la existencia de sus formas y dinámicas de organización económica, política y social, sintetizado en lo que pudiera considerarse como un culturicidio razonablemente civilizador, pues si lo propio era impropio, lo ajeno se institucionalizó como propio y auténtico, creando nuevas figuras simbólicas ensambladas desde la estética de la colonialidad mediante la pedagogía civilizadora. ${ }^{18}$ Ante el desarrollo de aspiraciones y expectativas económicas y políticas se ha logrado establecer los límites necesarios para que se entienda la racionalidad como una singularidad al demarcar un orden mundial civilizatorio sustentado en la taxonomía del conocimiento y en la superioridad de saberes sobre otros saberes que, incluso, ocurrieron primeramente.

Asimilar esta complejidad de hechos no implica necesariamente una separación radical entre las regiones productoras de saberes de las nuestras; difícilmente se 
podrá pensar una filosofía local retraída de la tradición euro-estadounidense, en todo caso, resulta relevante examinar los puntos de quiebre de la dominación contenida en esas perspectivas. Este desafío, como otros contenidos en el debate sobre el pensamiento latinoamericano, coincide con el reconocimiento de una textualidad centrada en la importación de saberes, donde el otro-originario, el ser-humano, puesto desde la perspectiva colonial ${ }^{19}$ sobre esos mundos noeuro-estadounidenses, era y es reconocido como carente de historia, sujeto a un peritaje de su condición humana, del goce de la espiritualidad y de lo culto como rigor de civilidad, pero nunca de sabiduría, nunca de cultura, convertido en un sujeto histórico de la subalternidad (cfr. Guha, 2002; Beverley, 2011).

Adoptar una actitud decolonial significa comprender desde dónde emergen las lógicas y las sensibilidades propias de nuestros pueblos originarios, de aquellos seres que antecedieron nuestra vida de hoy, rebosados de experiencias, significados, simbolismos, acciones, relaciones, afectos y prácticas que forjaron desde sus cotidianidades esa sabiduría de la que apenas tenemos un tiznado boceto anclado ligeramente en nuestra memoria latinoamericana. Tampoco podemos pasar por la experiencia de ser-latinoamericano de espaldas ciegas a la realidad hegemónica construida por la lógica moderno-capitalista impresa en la práctica neoliberal. Encontrar nuestra-América es inaplazable, comporta asumir la "discontinuidad de las fronteras, de las experiencias coloniales" (Mignolo, 2003, p. 29), nacidas desde la herida colonial provocada por la conquista invasiva de las tierras americanas, pero también desde el locus colonialista sembrado en la Europa del Sur, África y Asia. Es compromiso relevante, promover un diálogo intercultural y trans-indisciplinario de saberes donde se incluya la discusión, las problematizaciones derivadas de las experiencias territoriales, sociales y culturales emplazadas en la geopolítica mundial del eje sur-sur, dibujada desde una geometría de poderes enraizados en los conflictos y las luchas experimentadas al sur del imaginario dominante del norte.

Esto hace necesario producir un diálogo permanente de saberes desde el re-encuentro valorativo de los lugares de enunciación de esas textualidades concurrentes con la lógica de la dominación de la colonialidad, sobre todo, reconociendo debates filosóficos y humanistas concebidos desde tales racionalidades y constituidos como enfoques contra-hegemónicos colindantes con los cuerpos de saberes del 
pensamiento latinoamericano, de los cuales urge que la investigación se encargue en distintos contextos y perspectivas. Estos argumentos pueden orientar la acción filosófica hacia el humanismo y la desalienación presente en distintos momentos y contextos históricos del desarrollo intelectual de nuestros pueblos, por lo que es imperante apropiarse de una misión común para el avance de las ideas latinoamericanas, situar al ser latinoamericano en niveles diversos de humanización, concienciación y liberación como proyectos políticos de trascendencia histórico-epistemológica (Guadarrama González, 2008; Miró Quesada, 1976; Dussel, 1996, 1998).

\section{Hacer investigación sobre el pensamiento latinoamericano}

Hacer investigación sobre el pensamiento latinoamericano es una tarea fundada en el compromiso creativo ante los desafíos presentados por la comprensión del territorio y del ser-americano dentro de los márgenes de la latinidad, que gira en torno a los significados de la lucha originaria contra el despojo del propio territorio y sus implicaciones en la formación de la personalidad, el carácter, la identidad y la ciudadanía de los cuerpos sociales latinoamericanos. El consecuente compromiso implícito en la creación metodológica y en la misma discusión filosófica radica en problematizar, localizar, contextualizar y articular los caminos para producir conocimientos arraigados al sentir-pensar raizal requerido para tensionar los relatos científicos moderno-coloniales. Pensamos en una metodología para la investigación sobre el pensamiento latinoamericano en, desde y para el territorio latinoamericano fundamentada y organizada sobre el reconocimiento de la génesis de sus luchas, revoluciones y resistencias ocasionadas desde las heridas y fisuras resultantes de la violencia conquistadora iniciada desde el encubrimiento de América, tal como lo plantea Dussel (1994), pero también a partir de la convivialidad forjadora de sabidurías y culturas que constituyen en sí mismas conocimientos producidos históricamente, social y culturalmente orientados a profundizar la autodeterminación de los pueblos y la preservación de sus emancipaciones y soberanías ideológicas, así como de sus libertades, tal como operó en los ilustrados proyectos independentistas y emancipadores.

Estas razones sirven de anclaje para señalar la problematización como un asunto medular en la creación de una metodología para la investigación, donde se 
puedan elaborar diferentes dominios de hechos, de prácticas y de ideas mediante la relación entre pensamiento y mundo-concreto, o entre el análisis y lo que es analizado. Como estrategia analítica sobre la historia crítica del pensamiento, la problematización permite convertir esa historia crítica en objeto de pensamiento en sí mismo desde el cual ese objeto focaliza la práctica discursiva analítica, a través del establecimiento de una serie de normas y regulaciones que actúan sobre la verdad de los hechos (Foucault, 1999, 2005; Deacon, 2000; Restrepo, 2008).

Sobre todo, que permita justificar el entendimiento del conocimiento y las culturas desde su expresión humana e impulsar una actitud humanista que permita la comprensión entre semejantes y coterráneos (Zea, 1975); a la vez, que se deslinde de metodologías prefabricadas y se ocupe de comprender el contexto en el que se conceptualiza y proyectan las problematizaciones emergentes en el campo de las acciones humanas colectivas, enfatizando en la investigación como un campo de valores, prácticas y de relaciones de poder (cfr. Tuhiwai Smith, 2016). Sandoval (2000) plantea que las metodologías deben representarse como una estructura teórico-metodológica de conciencia de oposición, de resistencia enfocada en la igualdad de derechos, de carácter revolucionario, como metodología de los oprimidos para los subalternizados de la dominación; esta fórmula sugiere una metodología para la emancipación compuesta por habilidades semióticas, deconstructivas, meta-ideológicas, democráticas y de concientización diferenciada.

Cuando quien "investiga" el pensamiento latinoamericano adopta la problematización como guía para el camino - lo metodológico_- emprende la tarea de deshilvanar una realidad pluridiversa que acaudala lógicas, discursos y prácticas, hechos y eventos, desde lo cual se pueden orientar los caminos hacia el reconocimiento de los contextos y lugares desde donde se producen esas formas de saber. Estas, imperiosamente, deben romper los amarres con la euro-estadounidización de la subjetividad y sus acciones simbólicas y materiales, conduciendo la acción filosófico-metodológica a develar las funciones determinantes del contexto en la especificidad de las relaciones y articulaciones que enmarcan los procesos de producción de lo real, de la vida y las relaciones con el mundo histórico descrito desde las relaciones de poder emplazadas en los trazos culturales de la autenticidad e identidad latinoamericana, las cuales fueron supeditadas a las intransigencias metropolitanas sobre nuestros territorios y nuestros pueblos. 
Si la investigación como actividad intelectual nos acerca a comprender lo latinoamericano como mero objeto de estudio, se entiende por demás que su carácter contextual representa un mapeo de relaciones históricas y culturales con atributos específicos que convergen y divergen, a la vez que determinan la manera en que se enfoca el mundo, la realidad, los seres humanos y sus vidas.

Filosofar es en sí mismo un hecho investigativo es un acto que promueve la liberación de la conciencia, el cultivo del espíritu y la formación de las fuerzas humanas para el debate acerca de la superación y el bienestar humano y social; se trata de "pensar todo a la luz de la palabra interpelante del pueblo" (Dussel, 1996, p. 207), desde las voces de las víctimas de la conquista, pensar desde el dolor de la diferencia colonial, desde la vida de los condenados de nuestros territorios. Hacer filosofía como compromiso desalienante y emancipador es una acción donde la filosofía se transforma en la crítica de toda crítica, con un certero sentido de validez, una eficaz capacidad teórica constructiva, abordando la realidad como problema y articulación de eventualizaciones (Grossberg, 2009); sobre todo, se trata de investigar de modo colectivo y originario, pues:

uno conoce, naturalmente, desde lo que es (...) y, por tanto, la sociedad no se hace susceptible de ser realmente conocida sino cuando se ha totalizado, es decir, cuando ya nada sucede en ella con autonomía, cuando todo ocurre con referencia a lo demás, cuando, en suma, todos producen para todos. (Zavaleta, 2009, p. 68)

Una metodología para la investigación filosófica del pensamiento latinoamericano debe comprometerse a "hacer, deshacer y rehacer relaciones y contextos, a establecer nuevas relaciones a partir de viejas relaciones o de no relaciones, a trazar líneas y mapear conexiones" (Grossberg, ob. cit., p. 29); esta metodología se ocupa de provocar el surgimiento de la crítica al historicismo y a sus periodizaciones categoriales sustantivas del encapsulamiento tribal de escuelas de pensamientos, de tribus académicas, dedicadas a definir identidades e ideologías acompasadas a proyectos políticos determinados. Cuando se promueva la articulación de eventualizaciones en la investigación latinoamericana, seguramente, ocurrirán ideas y acciones casadas con la crítica profunda a la singularidad contenida en las constantes históricas y los universales metafísicos, ambos, como definiciones previamente establecidas (Restrepo, 2008). 
Entre los retos planteados a la investigación sobre el pensamiento latinoamericano es necesario esclarecer el hecho de que el pensamiento latinoamericano es prolijo por su misma naturaleza inédita y fundadora de sistemas de ideas que han trascendido la historia de nuestros pueblos; esas textualidades que nos interpelan a través del valor de los saberes ancestrales, se recrean en las narrativas del presente buscando las posibilidades de entender cómo operan los sistemas del orden civilizatorio mundial y entrar en diálogo con las fuerzas opresoras que descuartizan la libertad de ser humano de ser conscientes, de ser libres. Las formas que asume la investigación desde las lógicas del pensamiento latinoamericano vienen definidas por "la marcada preocupación política y por el vínculo con los problemas sociales de cada época y circunstancias, hoy menos que nunca [existen] motivos para estimular actitudes evasivas de academicismo estéril, asepsia ideológica y neutralidad axiológica" (Guadarrama González, 2008, p. 148).

La investigación es un campo activo ampliamente popularizado entre diversos sectores del quehacer diario, es propio de todas las personas investigar por qué ocurren los hechos, además de las condiciones y consecuencias en las que estos se presentan en eso que llamamos realidad concreta. Por su parte, la cultura academicista, científica por naturaleza, universal por decreto hegemónico de dominación, ha impuesto rigores metódicos para organizar de manera homogénea la producción de conocimiento, y la filosofía como campo de pensamiento humano está dentro de esta cofradía intelectual y política que se ha reproducido históricamente, creando unas visibilidades pero, también, invisibilidades sustantivas.

En torno a las visibilidades producidas, éstas emergen dentro del marco referencial de una lógica universal del conocimiento y sus formas de producción, encunadas en la antigua tradición filosófica e identificada como la primera forma humana de filosofar, desde la cual se dio paso a la evolución, casi que por etapas, de un encadenamiento de lógicas siempre adosadas a las formas euro-estadounidenses de comprender el mundo, la realidad y la humanidad, sus orígenes, problemas y alternativas. Con bastante precisión, suele resaltarse la universalidad de la ciencia y del conocimiento generado en esos límites geopolíticos y convertidos en patrones hegemónicos de dominación filosófica, teórica y metodológica; por lo cual, sólo era y sigue siendo validado como conocimiento admitido universalmente aquel 
construido dentro de tales límites y nunca fuera de ellos, a la vez que posicionaba a sus creadores y poseedores como figuras emblemáticas de un saber cosificado y reproducido técnicamente mediante el artilugio de la aplicabilidad de sus principios reguladores.

Dussel (1998) señala que la distribución global de la intención filosófica se esquematiza mediante una fórmula interregional que tiene su punto de origen en el sistema asiático-africano-mediterráneo, no precisamente se halla en la cosmogonía greco-latina, y la América se constituyó en periferia histórica mundial a partir del siglo XV, precisamente, por el tránsito comercial promovido por el espíritu de la conquista que trajo consigo un proyecto civilizatorio, alienante e ideologizante. Repartido el mundo, su geografía con sus economías, políticas y ciencias, hicieron su trabajo de ordenamiento del sistema de convivencia y de conocimiento, para lo cual la figura maquínica del Estado se erigió para asegurar el bienestar del sistema del orden civilizado global; en este banquete, la filosofía tuvo su buena participación ofreciendo su valorada labor, el atesoramiento de la sabiduría humana al cumplimiento de los propósitos de los grandes centros mundiales, pero también el orden y el control de los cuerpos sociales.

Walter Mignolo destaca que "la geopolítica del conocimiento necesita tener en cuenta las relaciones, por un lado, entre conocimiento y colonialidad y, por otro, las existentes entre los diferentes "rangos" (...) en la producción, distribución, adaptación de conocimientos y de conflictos epistémicos" (Mignolo, 2003, pp. 2728); es decir, aborda las relaciones de poder y dominación inscritas en la lógica universal de la modernidad, asumidas como mecanismo y estrategias de poder y control para encauzar el determinismo funcional en los diferentes ámbitos de la vida social: la religión, la constitución de la familia, las políticas públicas, la educación, la distribución del trabajo y la intimidad personal (Quijano, 2007); por ello, es comprensible la existencia del paralelismo entre la geopolítica del conocimiento y la geopolítica económica, lo cual resulta ser un engranaje difícilmente disoluble.

Estos planteos surgen a propósito de la idea de que el pensamiento latinoamericano, entendido como un anclaje propio del campo histórico-filosófico y literario, se ha desarrollado sobre un corpus teórico-metodológico apegado a los cánones establecidos en diferentes momentos históricos y culturales, o ha sido secuestrado por testaferros de la ciencia para hacerlo parte de sus estrategias de dominación, 
desarrollado con mayor fuerza desde mediados del siglo XX y lo que transcurre del XXI a través de la semiótica digital de la folclorización de la cultura originaria.

En los espacios universitarios consagrados a la formación académica, profesional, crítica y reflexiva, existen vacíos permanentes para la producción y discusión sobre el pensamiento latinoamericano, muy a pesar de que el compromiso político de estas instituciones está orientado a la formación de 'un ser integral' que responda a los desafíos locales con alta calidad intelectual y humana: aun así, se evita hurgar en las raíces de los pensamientos propios y, generalmente, se busca anclar tales producciones en los estancos de las teorías y metodologías hegemónicas desarrolladas como parte del proyecto geopolítico global del conocimiento, asociado a la síntesis interpretativa producida por la mediática global. Probablemente, una suerte de razón de ser de este asunto se pueda encontrar en la invisibilidad del pensamiento latinoamericano en el desarrollo de la cultura académica local, más si se considera que muchos de los 'filósofos latinoamericanos' lo eran por ser propios de estas tierras, pero su formación académica la compartieron en escenarios europeos y/o norteamericanos, incluso, desde esas latitudes siguen pensando nuestra-América, además esta 'corporación de intelectuales pensadores' latinoamericanos tiene una mayoría representativa de hombres y poca de mujeres.

De allí la importancia de la advertencia hecha por Arturo Ardao sobre la función actual de la filosofía latinoamericana, donde señala que el saber filosófico propio se ha basado en el consumismo filosófico y no en la producción filosófica, mientras exhorta a girar la acción filosófica: "a eso se tiende en la medida que el latinoamericano, sujeto del conocimiento filosófico, lo es cada vez más en el carácter de sujeto del filosofar, en un cambio de sentido del ejercicio de la inteligencia" (Ardao, 1976, p. 17). Este exhorto, a juicio propio, puede iniciarse a partir de la evaluación de la relación historia-filosofía y cómo se fue construyendo un imaginario sobre la intelectualidad de nuestros-pueblos; es común en la literatura buscar vinculaciones establecidas entre ambos campos disciplinarios al punto de instaurar determinismos universales a partir de esa relación. Lo que sí se nota con total claridad es la inseparable relación entre estos campos y el requerimiento de transdisciplinarizar esta relación para evitar los dogmatismos que sugiere cada uno por separado, entendidos en la noción de escuelas, períodos, perspectivas de análisis, metodologías. 
Dada la complejidad de esta problemática es importante examinar las maneras de generación de esa trans-in-disciplinariedad entre historia-filosofía. Primeramente, es importante tomar en cuenta que toda forma de pensamiento y de acción humanas tiene un contexto, un contexto formado y figurado por los relatos históricos, económicos, políticos y culturales desarrollados en un tiempo histórico específico, es inferir que nuestras cotidianidades pudieran ser otras si los contextos en los que estas se desarrollaran fueran otros, lo cual supone un problema filosófico de mayor complejidad que tensionaría la marginalidad de los utopismos. Las respuestas esperadas de la filosofía tendrían que orientarse por la realidad de los pueblos a los que esta les sirve de fundamento, y esa es una tarea liberadora en sí misma; ${ }^{20}$ "lo innegable es que la conciencia latinoamericana incluye específicas connotaciones de historia continental y universal, que la han hecho y la hacen obrar -aun en un mismo sujeto- con una entonación y un alcance psicológicos diferentes" (Ardao, 1980, p. 9, destacado en el original), por lo cual una forma trans e indisciplinaria de comprender esta relación reside, más bien, en reconocer los procesos de formación de la conciencia histórica del pensamiento, ello sin ataduras a principios academicistas, ni vínculos estáticos a períodos o etapas históricas sustentadas en la longitudinalidad en la que se busca encarcelar el tiempo y el espacio desde la geopolítica dominante del conocimiento, que no coincide con la vivencia de nuestros pueblos.

Definitivamente, la fundamentación temporal y espacial presentes en la investigación académica, sea en filosofía o en cualquier otra ciencia, responde a criterios de regulación del orden civilizatorio fundado sobre las estrategias de poder inscritas en sus corpus teóricos y metodológicos, específicamente en aquellos de inspiración liberal-ilustrada. ${ }^{21}$

Coincidiendo con Enrique Dussel (1977), la investigación sobre el pensamiento latinoamericano, tal como está esbozada en estas páginas, se prefigura como una actividad pedagógica en sí misma e involucra un método dinámico-pluralactivo para confrontar los problemas y temas que son de ocupación de nuestros pueblos. Ello significa quedar en el silencio y favorecer la escucha de la voz del Otro que penetra desde la exterioridad; y también, asumir la acción filosófica como una pedagógica de la liberación, vivida como un compromiso orientado a enseñar "críticamente el valor de su gesto y permite teóricamente la apertura del camino" (Dussel, 1977, p. 131). Una investigación filosófica del pensamiento 
latinoamericano desde la perspectiva de la pedagógica de la liberación supone, primeramente, una profunda comprensión de las dominaciones y las violaciones determinantes del buen-vivir y del vivir-bien; son encuentros con lo originario, lo raizal, lo propio, específicamente, con lo territorial y humano y desde allí se mira lo ajeno, lo otro, la exterioridad, para así contrarrestar los embates ofrecidos por las "fuerzas pragmáticas del actual orden tecno-utilitario mundial imperante [que trata] inútilmente de hacerla sucumbir” (Guadarrama González, 2008, p. 147).

Concebir una metodología para la investigación sobre el pensamiento latinoamericano es una oportunidad para ampliar los ámbitos del saber y extender una convocatoria a las distintas manifestaciones culturales (humanas) que emergen del pensar de nuestros pueblos; pensar como praxis de vida la liberación es poner en marcha el desarrollo lógico de las textualidades que retoñan en la experiencia originaria, raizal, que no tiene que ser entendida como lo ancestral propiamente, pero lo incluye, apoyada en una descripción dialógicamente producida de la historia nacional y la historia mundial donde convergen lo filosófico, lo racional (científico-tecnológico) y lo ético-sensible (artes y humanidades) para dibujar los trazos de una estética del pensamiento latinoamericano desde las luchas y las resistencias que nos unen y nos diferencian a la vez, desde la filosofía de la producción condicionada por la praxis de la vida propia.

En todo caso, las problematizaciones sobre el pensamiento latinoamericano son el inicio de un compromiso con la visibilidad universal de las luchas contrahegemónicas desarrolladas por nuestros pueblos. En ellas se pueden dilucidar los temas e hipótesis necesarios para orientar el camino de la indagación filosófica y la provocación para la producción teórica desde el sentir-pensar la misma praxis de la liberación, además de resignificar el valor del territorio en la determinación de los pueblos. Significa, también, que la investigación del pensamiento latinoamericano tiene que volver la mirada - de quienes investigan - hacia los compromisos de nuestros pueblos, sus luchas y resistencias con la redefinición crítica de la autenticidad, la identidad, la ideología del filosofar latinoamericano, en virtud de apuntalar los cimientos para una crítica de la praxis desde la misma praxis, desde la teoría de la praxis latinoamericana, también desde la política de esa praxis (cfr. Dussel, 1996, 2007). Un proceso de investigación, tal como se piensa en esta discusión, busca 
pensar sobre la posibilidad concreta y real de desfetichizar [lo propiamente filosófico], indisciplinando el conocimiento en virtud de mantenerlo en diálogo perenne con las relaciones de poder y hegemonías que se construyen de manera diversa en el seno del patrón colonial, suscrito por el sistema mundial capitalista, y desde las cuales se instituyen las órdenes políticas que regulan las fronteras geográficas y epistemológicas de una nación en armonía con otras. (Pérez Jiménez, 2014, p. 14)

\section{Notas}

1 "Nuestra América" en mayúscula fue acuñada en 1891 por José Martí para plantear que los pueblos vencieron a los letrados porque la batalla no era "entre la civilización y la barbarie, sino entre la erudición y la naturaleza" (Martí, 2005, p. 33). Para los propósitos de esta obra utilizaremos nuestra en minúscula pues se coloca el énfasis en los efectos de la gubernamentalidad impuesta por la razón del Estado burgués, liberal e ilustrado; aunque en el actual proyecto liberador, Nuestra América retoma su profundo sentido martiano" (Vázquez y Pérez Jiménez, 2012, p. 7). Esta cita fue incorporada como nota de pie de página en el texto referido al emplear la frase martiniana para especificar la constitución e institucionalidad del Estado liberal en la gubernamentalidad venezolana; tal como se indica en el texto de la cita, y sigue estando vigente en el presente trabajo, "nuestra" seguirá estando en minúscula a propósito de los efectos y consecuencias derivados de la conquista y la colonialidad sobre lo que es considerado realmente como nuestro, por ser paridos por esta tierra americana, lo cual se nos fue negado por las ambiciones de la monarquía ibérica, traducidas en imposiciones para el arrebato de lo ajeno y la dominación servil de sus poseedores, luego naturalizadas por la economía y política liberal-ilustrada y su consecuente cuerpo científico. Esta forma discursiva, nuestraAmérica, recupera el sentido ontológico de la herida colonial y se amarra entre sí mediante un guión (-) que procura resaltar la necesidad de formar conciencia sobre la naturaleza y la significancia de la americanidad que nos es propia, originaria y raizal, y es esta experiencia la que motiva el uso de esta idea de Martí.

${ }^{2}$ La forma semántica euro-estadounidense refiere con rigurosa especificidad a la geopolítica del conocimiento suscrito a la distribución del territorio americano a partir de la conquista, según la cual, la razón europea, encarnada en los conquistadores, "descubrió" lo otro desconocido, lo americano, luego entendido 
como lo latinoamericano. Y siendo, posteriormente, los Estados Unidos ejemplo de república civilizada, se convirtió en imagen de una racionalidad admirable, sobre todo por ser la primera zona continental en ver la luz de la libertad ante el yugo de sus colonos ingleses, franceses y unos pocos españoles. Lo que se busca con esta forma de mencionar este eje de la dominación es señalar la influencia determinante de dos zonas continentales reunidas por fines conexos y vinculantes sobre el resto de la geografía americana, las cuales han sido creadoras y reproductoras de una ideología homogénea y hegemónica centrada en valores específicamente derivados de la racionalidad moderna de totalidad, universalidad y normalidad para que los pueblos se encaminen por la ruta del orden y del progreso con miras a pactar con el desarrollo y la modernización y, así, a la apertura de los territorios nacionales a la comercialización y diplomacia europea y estadounidense; y aunque existen distinciones entre ambas dimensiones geográficas, en este trabajo nos referiremos a la unidad formada para el logro de fines particulares, actualmente contenidos en los relatos del capitalismo global y el neoliberalismo.

${ }^{3}$ En este trabajo se entiende la subalternidad como un atributo simbólico/concreto general de subordinación incardinado en el sujeto histórico colonial, indicado mediante categorías residuales de significación inscritas en las semióticas de la dominación, las cuales se expresan en términos de clase, raza, sexualidad, trabajo, profesión o de cualquier manera conocida que implique una separación importante al interior y exterior de las organizaciones sociales compuestas por una lógica específica, pero determinada por la estructuración diseñada desde las relaciones de poder. La subalternidad implica la politización del colonizado, ese sujeto que emerge de las élites indígenas en su forma de burguesía nacionalista; pues, “paralelamente al ámbito de la política de la élite, existió durante todo el período colonial otro ámbito de política india en que los actores principales no eran los grupos dominantes de la sociedad indígena ni las autoridades coloniales, sino las clases y grupos subalternos que constituían la masa de la población trabajadora, y los estratos intermedios en la ciudad y el campo, esto es, el pueblo" (Guha, 2002, p. 36). Una nota aclaratoria sobre el sentido y uso del término subalterno, entre otros, se encuentra en la misma obra en las páginas 41 y 42 y, asimismo, en Spivak (1988, pp. 3-32) y Beverley (2011, pp. 33-70), donde se expone un análisis sobre la subalternidad y las formas de enunciación contenidas en la historia academicista y en los relatos políticos sobre el Estado, y se resalta la comprensión 
latinoamericanista que hace el autor sobre las reflexiones indias propuestas por Spivak y Guha, principalmente.

${ }^{4}$ Resignificar la noción de gente sin historia es establecer una correlación epistémica y ontológica sobre la comprensión teórico-metodológica acerca de la noción de sujeto histórico y la creación histórica, respecto a ciencia, teorías y métodos. No obstante, intentamos designar con esta frase la invisibilidad de la imagen de nuestros pueblos originarios de la estructura arbórea científica, la cual refiere a nuestros antepasados como un pueblo súbdito, guerrero y buscador de libertades y emancipaciones. Evidentemente, esto pone en cuestión el hecho de que aquellos que tenían y hacían la historia, los conquistadores, primero europeos y luego euro-estadounidenses, eran los dominadores, los cultos pacifistas y los hombres libres y libertadores; con ello, se suscribe un problema discutido desde la historia insurgente, crítica y liberadora que no es objeto de este trabajo. Esta expresión surge del planteamiento de Eric Wolf, quien declara: "La expresión 'la gente sin historia' no me pertenece: se remonta al siglo XIX. Marx y Engels la utilizaron para señalar su falta de simpatía por algunos movimientos nacionales separatistas de Europa oriental. Mi pretensión era ser irónico, pero algunos lectores no lo advirtieron. 1o que me proponía era cuestionar a quienes creen que los europeos fueron los únicos que hicieron historia" (Wolf, 2006, p. 2). El autor complementa su argumento al decir que "las sociedades y las culturas humanas no podrán comprenderse verdaderamente mientras no aprendamos a visualizarlas en sus interrelaciones e interdependencias mutuas, en el tiempo y el espacio" (p. 2). De allí la justificación de la incorporación de esta acepción como una significación indisciplinada del sujeto histórico creado en la narrativa de la conquista y la colonia.

${ }^{5}$ Para efectos de esta discusión, entenderemos la narrativa modernidad-colonialidad como la dialéctica discursiva entre lógicas complementarias que indican cómo un cuerpo de conocimientos - primero religioso y luego científico- penetró las prácticas conquistadoras mediante la violación humana y la violencia cognitiva, establecidas como bandera en el impulso del desarrollo de las textualidades de dominación, explotación y racismo circulantes por más de 500 años en la racionalidad-sensible latinoamericana. Puntos de vista precedentes se constituyen por los aportes de Inmanuel Wallerstein, Aníbal Quijano, Enrique Dussel, Walter Mignolo; sin embargo, para una lectura con mayor precisión testimonial, es primordial revisar Castro-Gómez y Grosfoguel (2007) y Escobar (2003). 
${ }^{6}$ Para efectos de esta discusión, entenderemos la narrativa modernidad-colonialidad como la dialéctica discursiva entre lógicas complementarias que indican cómo un cuerpo de conocimientos — primero religioso y luego científico- penetró las prácticas conquistadoras mediante la violación humana y la violencia cognitiva, establecidas como bandera en el impulso del desarrollo de las textualidades de dominación, explotación y racismo circulantes por más de 500 años en la racionalidad-sensible latinoamericana. Puntos de vista precedentes se constituyen por los aportes de Inmanuel Wallerstein, Aníbal Quijano, Enrique Dussel, Walter Mignolo; sin embargo, para una lectura con mayor precisión testimonial, es primordial revisar Castro-Gómez y Grosfoguel (2007) y Escobar (2003).

${ }^{7}$ Un argumento orientado en la misma línea de discusión expuesta por el venezolano Federico Brito Figueroa, lo encontramos en Seguridad, territorio, población de Michel Foucault; mientras el francés esboza la genealogía del liberalismo, el venezolano explica los mecanismos y procedimientos adoptados para ordenar el territorio americano en la época colonial. Foucault proyecta las clases de su curso de 1978 sobre el estudio del biopoder, a su vez anclado a la discusión de los sistemas de seguridad que definen el espacio urbano, específicamente la ciudad, cuyo propósito era ordenar y controlar la población y las individuales sometidas a los dispositivos de seguridad y los mecanismos disciplinarios que emergieron en los siglos XVII y XVIII, particularmente, con el florecimiento de la regulación científica de la economía y del liberalismo; estos aspectos Foucault los continúa en su curso intitulado Nacimiento de la Biopolítica. (cfr. Foucault Seguridad, territorio, población).

8 Michel Foucault, en sus clases intituladas Seguridad, territorio, población, considera el territorio como una estructura vinculante entre las tecnologías de seguridad y control sobre la población que, asociadas a la soberanía como ejercicio jurídico dentro de los límites del territorio, ejemplificados a través de la formación de las ciudades y posteriormente de la economía, dan corporeidad a su genealogía del liberalismo. Aunque no fue una categoría primordial en el trabajo foucaultiano, sus razonamientos sobre el territorio permiten materializar y problematizar sobre la gubernamentalidad, en cuanto emplazamiento de un mecanismo primario en la escala de las relaciones de poder - el biopoder — que permite la resignificación del sujeto, la población y sus necesidades en el marco de una práctica de jurisdicción 
dirigida desde la razón del Estado, específicamente, desde la formación de la lógica liberal (ver Foucault (2006), p. 15 y sucesivas; se recomienda revisar las clases de los meses enero y febrero de 1978).

${ }^{9}$ Para una discusión de mayor alcance, es importante revisar los planteamientos de Arturo Ardao, Edmundo O'Gorman y Miguel Rojas Mix, pues, sin lugar a dudas, nombrar el territorio evidencia una coyuntura política de las relaciones de poder que se iban levantando con fuerza en el viejo continente entre las "potencias" europeas en relación a la disputa de sus territorios y, en adelante, de los nuevos conquistados. En este sentido, siempre convino determinar un nombre que implicara garantía de propiedad y, a la vez, una semántica del territorio y sus bienes, pero también que significara una distribución de poderes, del continente y de nacionalidades, siempre vistas desde la perspectiva del otro-europeo: "La expresión América Latina como sustantivo compuesto designa al conjunto de las Américas de lenguas española, portuguesa y francesa" (Ardao, 1980, p. 23). Incluso, al proseguir con el análisis del pensamiento de Michel Chevalier, Ardao cita y subraya la idea de que "las dos ramas, latina y germana, se han reproducido en el Nuevo Mundo. América del Sur es como la Europa meridional, católica y latina. La América del Norte pertenece a una población protestante y anglosajona" (p. 55). Por su parte, Edmundo O'Gorman sintetiza sus planteamientos expuestos en la obra La Invención de América, publicada por primera vez en 1958, de la siguiente manera: "la idea de que el surgimiento de ese ente [llamado América] fue el resultado de un proceso inventivo gestado en el seno de la arcaica y cerrada concepción tripartita del mundo geográfico-histórico, proceso que culminó en la ideación de las nuevas tierras como 'cuarta parte' del mundo y que, al poner en crisis de fundamentos aquella antigua manera de entenderlo, la sustituyó, a su vez, por una concepción abierta que abrazó, por lo pronto, a la totalidad del globo terráqueo como domicilio cósmico del hombre, y en el límite, a todo el universo. Congruente con esa idea, llamé a ese proceso el de la 'invención de América” (O’Gorman, 2002, p. 15).

${ }^{10}$ Aunque se entiende que la alfabetización y la evangelización fueron la estrategia de dominación de la conquista, es importante afirmar que alfabetizar y evangelizar fueron acciones propias de las intenciones conquistadoras y aún perviven con otros matices estéticos, pero con los mismos fundamentos ideológicos de control, dominación y expansión demostrados sobre el territorio americano por sus 
"fundadores" imperialistas, por tanto, no puede creerse que esos procesos son parte del pasado, al contrario, son acciones presentes desarrolladas en torno a contenidos ideológicos capitalistas, imperialistas y expansionista de los paísescentro sobre los países-periféricos. Esta dinámica ha operado como una pedagogía colonizadora permanente, incluso iniciada con la incorporación de la educación para la formación ciudadana de acuerdo a los proyectos políticos e ideológicos suscitados en diferentes momentos de la historia americana y su irrestricto apego a la cosmogonía euro-estadounidense, de quienes pretendían extraer las ideas más novedosas en formación republicana de ciudadanos aptos para la civilidad, la vida pública y el trabajo industrioso.

11 Sobre esta problematización se ha desarrollado buena parte de la agenda de discusión y debate de lo que se conoce como el programa de investigación modernidad/colonialidad latinoamericano, antes referenciado (ver nota 6); no obstante, la reflexión incorpora como fundamental la invención de América a partir de la conquista, sus implicaciones humanísticas, sociales y científicas, así como los hechos asociados al desarrollo económico-político de nuestros pueblos. Vale destacar que el sistema-mudo engloba la relación entre países de acuerdo a la clasificación geopolítica centro-periférica desde donde se definen las relaciones del sistema económico, el auge de la industrialización y la tecnología y la universalización de la razón de Estado liberal-ilustrada como textualidad modernocolonial; propiamente, "en América, sin embargo, hubo una destrucción tan vasta de las poblaciones indígenas y una importación tan abundante de mano de obra, que el proceso de periferización generó menos una reconstrucción de instituciones políticas y económicas, que su construcción, virtualmente ex-nihilo toda-parte (salvo tal vez en las zonas mejicanas y andinas). Incluso, desde el principio, la forma de resistencia cultural a las condiciones opresivas fue menos en términos de historicidad que en términos de un salto hacia la "modernidad" (Quijano y Wallerstein, 1992, p. 584).

${ }^{12} \mathrm{Al}$ respecto de los eventos asociados a los propósitos de la redacción de la Carta de Jamaica, documento al que hacemos referencia, es importante destacar que el territorio adquiere un sentido simbólico-concreto imprescindible para la reafirmación de la libertad; "Él [Bolívar] entiende la anfictionía como unidad entre pares, y sólo las naciones independizadas de España han de participar en ella. Las razones son muchas y las explaya a todo lo largo de su correspondencia 
$\mathrm{y}$ aun en sus discursos. Unidas por la misma lengua y tradiciones, las nuevas repúblicas podrían constituir, confederadas, formidable muro de contención ante toda pretensión imperial. Separadas, seguirían siendo simples proveedoras de materias primas, con gobiernos mediatizados. Juntas podrán alcanzar autonomía y grandeza, menos por su extensión o riquezas que por el ejercicio de la libertad" (Pereira, 2015, pp. 64-65). Por su parte, también destaca la visión que tenía Bolívar del espacio geográfico universal y la diferencia entre los mundos asentados en el sistema mundial señalados por sus prácticas e intereses gubernamentales, tal como lo plantea Nweihed (1984).

${ }^{13}$ Este argumento se vincula con los planteamientos hechos por Enrique Dussel sobre la visión ontológica y fenomenológica de los viajeros exploradores que salieron en búsqueda de nuevas tierras, entre esos destacan sus análisis sobre las experiencias vividas por Colón y de quienes fungieron como colonizadores de los territorios nativos americanos, enfatizando en la experiencia desarrollada por Hernán Cortés; por tanto, remitimos a la lectura de la Conferencia 2: De la “invención” al "descubrimiento” del Nuevo Mundo (Dussel, 1994).

${ }^{14}$ El destacado es nuestro para evidenciar la claridad política y estratégica de Bolívar ante la figura hegemónica de la metrópoli, por ello es importante continuar la lectura de sus ideas: "De aquí nacía un principio de adhesión que parecía eterno; no obstante que la conducta de nuestros dominadores relajaba esta simpatía; o, por mejor decir, este apego forzado por el imperio de la dominación. Al presente sucede lo contrario; la muerte, el deshonor, cuanto es nocivo, nos amenaza y tememos; todo lo sufrimos de esa desnaturalizada madrastra. El velo se ha rasgado, ya hemos visto la luz y se nos quiere volver a las tinieblas; se han roto las cadenas; ya hemos sido libres y nuestros enemigos pretenden de nuevo esclavizarnos. Por lo tanto, la América combate con despecho, y rara vez la desesperación no ha arrastrado tras sí la victoria” (p. 64).

${ }^{15}$ El racismo de estado es abordado de manera transversal en las actividades de la Línea de Investigación "Representaciones, actores sociales y espacios de poder", en todo caso como categoría medular para la comprensión histórico-epistemológica de la formación, institucionalización y constitucionalización del estado liberal e ilustrado desarrollado por las ideas burguesas de la ilustración económica y política, 
específicamente. En un trabajo aún sin publicar, el autor de este texto plantea la discusión del racismo de estado en los escenarios educativos, apoyado en las ideas kantianas y hegelianas sobre el color de la razón, y en la reproducción pedagógica de un discurso a favor del blanqueamiento de las subjetividades mediante estrictos planes de formación educativa y profesional (Pérez Jiménez, 2017; cfr. Vázquez y Pérez Jiménez, 2012).

${ }^{16}$ Una discusión más amplia sobre la formación del Estado liberal-ilustrado en el discurso educativo establecido entre el siglo XVIII y XIX, se presenta en Vázquez y Pérez Jiménez (ob. cit., p. 39 y sucesivas).

${ }^{17}$ Al respecto de esta argumentación y su discusión, es válido plantear la originalidad implicada en el reclamo bolivariano sobre el estado del arte de las relaciones de dependencia inscrita en los cuerpos subjetivos originarios; decía el Libertador que “Los americanos en el sistema español que está en vigor, y quizá con mayor fuerza que nunca, no ocupan otro lugar en la sociedad que el de siervos propios para el trabajo y, cuando más, el de simples consumidores; y aun esta parte coartada con restricciones chocantes; tales son las prohibiciones del cultivo de frutos de Europa, el estanco de las producciones que el rey monopoliza, el impedimento de las fábricas que la misma Península no posee, los privilegios exclusivos del comercio hasta de los objetos de primera necesidad; las trabas entre provincias y provincias americanas para que no se traten, entiendan, ni negocien..." (Bolívar, 2010, p. 72). Además, este planteamiento sirve para alimentar la reflexión sobre el tratamiento del significado del proceso de subalternización propuesto en la nota al pie 2, y orienta la hipótesis de la formación de las mentalidades dependientes ocurrida por efecto de la pedagogización liberal-ilustrada y sostenida con fuerza por las narrativas moderno-capitalistas implícitas en las estéticas de la globalización neoliberal y multicultural.

18 Este desplazamiento de las significaciones culturales propias lo advirtió en Sociedades Americanas el maestro Simón Rodríguez, quien diestramente describía cómo la llegada de los 'cultos' iba poco a poco imponiendo nuevas formas de vida, nuevas prácticas de significación cultural: "Ya nuestros Sastres se ocupan en echar parches i remiendos, i nuestras Costureras en pedir limosna, porque nadie manda a hacer ni vestidos ni camisas - cada día llega una remesa de ropa 
hecha, i hasta de gorras para los Indios" (Rodríguez, 2010, p. 159). Y así, no sólo se fueron sustituyendo los oficios, los puestos comerciales por almacenes y establecimientos, no en vano surgió la creación de laboratorios, la realización de ferias industriales, la formación de ciudades, pues uno de los anclajes de la constitución de la humanidad también fue cambiado por otro sistema más refinado, la lengua y el idioma: "El pobre Castellano, al Cabo de 3 siglos i medio de guerra abierta, con los Indios i con los Negros (en la que ha padecido...lo que Dios sabe) ve llegar, de mar afuera, un refuerzo de enemigos que inundan el país i le toman las mejores posiciones" (Rodríguez, 2010, p. 160; cursivas nuestras, con el propósito de recalcar el significado histórico de la invasión de las ideas venidas de afuera, de tierras extranjeras, para la colonización de la conciencia americana).

${ }^{19}$ De acuerdo con el enfoque decolonial, pensar la razón y el ser sujeto colonial significa entender cómo se construyen las fronteras que separan las lógicas del colonizador de las del colonizado, interpretadas a partir de la colonialidad del poder; $y$, desde esas fronteras emerge un paradigma otro "porque tienen en común la perspectiva y la crítica a la modernidad desde la colonialidad", es "pensar a partir y desde la diferencia colonial” (Mignolo, 2003, p. 27).

${ }^{20}$ Afirma Francisco Miró Quesada: “La filosofía en nuestro medio está adquiriendo, a través de su propia creatividad, conciencia de su misión: contribuir a la liberación, pero no como puro instrumento pragmático, sino, reconociendo sus condicionamientos históricos y sus inevitables límites, como fundamento racional de la praxis" (1976, p. 98). Al respecto, Dussel hace un planteo similar, siguiendo Augusto Salazar Bondy, y afirma que, "la filosofía latinoamericana, o será una filosofía que piense el proceso de liberación, único proceso des-ideológico y real, o simplemente será una filosofía sofística y alienada, en el sentido de imitadora del centro y corroborante de la totalidad establecida, que piensa ideológicamente lo irreal” (Dussel, 1977, pp. 131-132).

${ }^{21}$ Para una discusión sobre el papel de la estructura de la gubernamentalidad del Estado ilustrado en Venezuela se puede consultar Vázquez y Pérez Jiménez (2012), especialmente, esta obra presenta evidencias histórico-epistemológicas sobre la determinación de los poderes de la dominación, entendida como una estrategia biopolítica operada desde los corpus científicos ilustrados-liberales 
como anclaje operativo de los regímenes civilizatorios. La propuesta es superar las estructuras y formas del conocimiento establecido por el orden jerárquico de las narrativas científicas reproductoras de una racionalidad universal y promotoras de una linealidad de relación entre el sujeto y el objeto, además representadas históricamente por una geopolítica imperial y colonial que situaba el conocimiento científico como un abstracto universal, deslocalizado, postulado como la "única forma válida de producir verdades sobre la vida humana y sobre los procesos de la naturaleza. Todas las demás epistemes fueron tenidas como 'precientíficas' (...), como formas de 'sabiduría popular' ancladas en una visión 'mítica' del mundo" (Castro-Gómez, Schiwy y Walsh, 2002, pp. 11-12). Esta discursividad se asienta en la colonialidad del saber, pensada y ejecutada desde un "tipo de pensamiento colonial sobre el mundo [que] obedece a un modelo epistémico desplegado por la modernidad occidental, [denominada] la hybris del punto cero" (Castro-Gómez, 2007, p. 79; énfasis en el original). Este saber se caracteriza por ser un pensamiento disciplinario yuxtapuesto a una organización arbórea de sus estructuras, originada por la constitución histórica de las disciplinas científicas producidas en la academia occidental y que favorecen la interpretación eurocéntrica del conocimiento colonial e imperial.

\section{Referencias}

Alberdi, J. B. (1915). Bases y puntos de partida para la organización política de la República Argentina. Buenos Aires: La Cultura Argentina.

Almarza, A. (2009). Limpieza de sangre en el siglo XVIII venezolano. Caracas: Fundación Centro Nacional de Historia.

Ardao, A. (1980). Génesis de la idea y el nombre de América Latina. Caracas: Centro de Estudios Latinoamericanos Rómulo Gallegos-Ministerio de la Secretaría de la Presidencia de la República.

Ardao, A. (1976). Función actual de la filosofía en América Latina. En AA.VV, La filosofia actual en América Latina (pp. 9-20) México: Editorial Grijalbo. 
Beverley, J. (2011). Políticas de la teoría. Ensayos sobre subalternidad y hegemonía. Colección Nuestra América. Caracas: Fundación Celarg.

Bohórquez, C. (2008). Pensar con cabeza propia (Prólogo a la edición venezolana). En P. Guadarrama, Pensamiento filosófico latinoamericano: humanismo vs. alienación (tomo I, pp. 9-16). Caracas: Fundación Editorial El Perro y la Rana.

Bohórquez, C. (2009). Prólogo. En J. M. Antepara, Miranda y la emancipación suramericana (pp. IX-XL). Caracas: Fundación Biblioteca Ayacucho.

Bolívar, S. (2010). La carta de Jamaica. En S. Bolívar (Ed.), Para nosotros la patria es América (2a edición, pp. 62-86). Caracas: Biblioteca Ayacucho.

Bosch García, C. (2006). Las ideologías europeístas. En L. Zea (coordinación e introducción), América Latina en sus ideas. (4ª edición, pp. 239-269). México: Siglo XXI Editores y UNESCO.

Brito Figueroa, F. (1973). El problema tierra y esclavos en la historia de Venezuela. Caracas: Asamblea Legislativa del Estado Aragua.

Castro-Gómez, S., y Grosfoguel, R. (2007). Prólogo. Giro decolonial, teoría crítica y pensamiento heterárquico. En S. Castro-Gómez y R. Grosfoguel (Compiladores), El giro decolonial: reflexiones para una diversidad epistémica más allá del capitalismo global (pp. 9-23). Bogotá: Siglo del Hombre Editores.

Castro-Gómez, S. (2005). La hybris del punto cero. Ciencia, raza e ilustración en la Nueva Granada (1750-1816). Bogotá: Editorial Pontificia Universidad Javeriana.

Castro-Gómez, S., Schiwy, F., y Walsh, C. (2002). Introducción. En C. Walsh, F. Schiwy y S. Castro-Gómez (Eds.), Indisciplinar las ciencias sociales. Geopolíticas del conocimiento y colonialidad del poder. Perspectivas desde lo andino (pp. 7-16). Quito: Universidad Andina Simón Bolívar, Ediciones Abya-Yala. 
Deacon, R. (2000.) Theory as Practice: Foucault's Concept of Problematization. Telos. Critical Theory of Contemporary, (118), 127-142.

Dussel, E. (1994). 1492. El encubrimiento del otro. Hacia el origen del "mito de la modernidad". La Paz: Plural Editores.

Dussel, E. (1998). Ética de la liberación en la edad de la globalización y de la exclusión. Madrid:Editorial Trotta.

Dussel, E. (1996). Filosofía de la liberación. Bogotá: Nueva América.

Dussel, E. (1977). Introducción a una filosofía de la liberación latinoamericana. México: Editorial Extemporáneos.

Dussel, E. (2007). Política de la liberación. Historia mundial y crítica. Madrid: Editorial Trotta.

Escobar, A. (2003). Mundos y conocimientos de otro modo. El programa de investigación de modernidad/colonialidad latinoamericano. Tabula Rasa, (1), 51-86.

Foucault, M. (1999). Estética, ética y hermenéutica. Barcelona: Ediciones Paidós.

Foucault, M. (2005). Historia de la sexualidad II. El uso de los placeres. España: Siglo XXI Editores.

Foucault, M. (2006). Nacimiento de la biopolítica (Trad. H. Pons, $1^{\mathrm{a}}$ reimpresión de la $1^{\mathrm{a}}$ ed. en español). Buenos Aires: Fondo de Cultura Económica.

Foucault, M. (2006). Seguridad, territorio, población (Trad. H. Pons, $1^{\text {a }}$ ed. en español). Buenos Aires: Fondo de Cultura Económica.

Grases, P. (2010). Prólogo. En Pensamiento político de la emancipación venezolana ( $1^{\mathrm{a}}$ reimpresión de la $1^{\mathrm{a}}$ edición, pp. IX-XVII). Caracas: Fundación Biblioteca Ayacucho. 
Grossberg, L. (2009). El corazón de los estudios culturales: Contextualidad, construccionismo y complejidad. Tabula Rasa, (10), 13-48.

Guadarrama González, P. (2008). Pensamiento filosófico latinoamericano: humanismo vs. alienación (Tomo I). Caracas: Fundación Editorial El Perro y la Rana.

Guha, R. (2002). Las voces de la historia y otros estudios subalternos. Barcelona: Crítica.

Martí, J. (2005). Nuestra América. Caracas: Biblioteca Ayacucho.

Mignolo, W. (2003). Historias locales-diseños globales: colonialidad, conocimientos subalternos y pensamiento fronterizo. Akal: Madrid.

Mignolo, W. (2007). La idea de América Latina. La herida colonial y la opción decolonial. Barcelona: Gedisa Editorial.

Miró Quesada, F. (1976). Función actual de la filosofía en Latinoamérica. En AA.VV, La filosofía actual en América Latina (pp. 85-98) México: Editorial Grijalbo.

Nweihed, K. (1984). Bolivar y el tercer mundo. La devolución de un anticipo revalorizado (Colección Bicentenario $\mathrm{N}^{\circ} 4$ ). Caracas: Comité Ejecutivo del Bicentenario de Simón Bolívar.

O'Gorman, E. (2002). México. El trauma de su historia (1 $1^{\mathrm{a}}$ reimpresión). México: CIEN de México.

Pease, F. (1980) Prólogo. En F. G. Poma de Ayala, Nueva corónica y buen gobierno (pp. IX-LXXXIX). Caracas: Biblioteca Ayacucho.

Pereira, G. (2015). Bolivar en Jamaica. La carta y otros desvelos. Caracas: Fundación para la Cultura y las Artes. 
Pérez Jiménez, C. (2014). Entre la idea de América Latina (de W. Mignolo) y los estudios culturales latinoamericanos: implicaciones para el marco político venezolano. Cuadernos Latinoamericanos, (42), 9-38.

Pérez Jiménez, C. (2017). La formación docente como práctica de liberación. Apuntes iniciales para una cartografía (trabajo de ascenso para optar a la categoría de profesor asociado). Universidad del Zulia, Maracaibo, Venezuela.

Poma de Ayala, F. G. (1980). Nueva corónica y buen gobierno. Caracas: Biblioteca Ayacucho.

Quijano, A., y Wallerstein, I. (1992). La americanidad como concepto o, América en el moderno sistema mundial. Revista Internacional de Ciencias Sociales, (134), 583-591.

Quijano, A. (2007). Colonialidad del poder y clasificación social. En S. CastroGómez y R. Grosfoguel (Eds.), El giro decolonial. Reflexiones para una diversidad epistémica más allá del capitalismo global (pp. 93-126). Bogotá: Iesco-Pensar-Siglo del Hombre Editores.

Restrepo, E. (2008). Cuestiones de método: «eventualización» y problematización en Foucault. Tabula Rasa, (8), 111-132.

Rodríguez, S. (2010). Inventamos o erramos. Caracas: Fundación Editorial El perro y la rana.

Sandoval, C. (2000). Methodology of the Oppressed. USA: University of Minnesota.

Sarmiento, D. (1915). Conflicto y armonías de las razas en América. Buenos Aires: La Cultura Argentina.

Spivak, G. C. (1988). Subaltern Studies: Deconstructing Historiography. En R. Guha y G. C. Spivak (Eds.), Selected Subaltern Studies (pp. 3-32). Delhi: Oxford University Press. 
Tuhiwai Smith, L. (2016). A descolonizar las metodologías. Investigación y pueblos indígenas. Santiago de Chile: LOM Ediciones.

Vázquez, B., y Pérez Jiménez, C. (2012). Estado liberal y gubernamentalidad en Venezuela. Caracas: Fundación Centro Nacional de Historia.

Wolf, E. (2006). Europa y la gente sin historia (1 ${ }^{\mathrm{a}}$ reimpresión de la $2^{\mathrm{a}}$ edición). México: Fondo de Cultura Económica.

Zavaleta, R. (2009). La autodeterminación de las masas. Bogotá: Siglo del Hombre Editores, CLACSO.

Zea, L. (1986). El positivismo. En Pensamiento Positivista Latinoamericano $N^{\circ}$ 71. Caracas: Biblioteca Ayacucho.

Zea, L. (1975). La cultura y el hombre de nuestros días. Caracas: Instituto Pedagógico. 